\title{
CONSTRUÇÃO E CARACTERIZAÇÃO DE UM DETECTOR ELETROQUÍMICO PARA ANÁLISES EM FLUXO
}

\author{
Wallans Torres P. dos Santos, Eduardo F. Azevedo, Eduardo M. Richter e Yaico D. Tanimoto de Albuquerque* \\ Instituto de Química, Universidade Federal de Uberlândia, 38400-902 Uberlândia - MG, Brasil
}

Recebido em 5/3/09; aceito em 29/5/09; publicado na web em 10/11/09

\begin{abstract}
CONSTRUCTION AND CHARACTERIZATION OF AN ELECTROCHEMICAL DETECTOR FOR FLOW ANALYSIS. The present work describes a low-cost electrochemical "wall-jet" detector for flow analysis. The electrolytic solution enters into the cell through a tube of stainless steel (200 to $300 \mu \mathrm{m}$ i.d), reaching to the center of the working electrode perpendicularly and then being mixed to the remaining solution in the cell, which flows under atmospheric pressure into a waste reservoir. The proposed electrochemical detector can be used with any type of working electrode, from commercial to home-made, such as glassy carbon and metallic electrodes (modified or unmodified), which enlarge the applications of the electrochemical detector.
\end{abstract}

Keywords: electrochemical detector; flow analysis; wall-jet cell

\section{INTRODUÇÃO}

Entre os detectores acoplados a sistemas de análise por injeção em fluxo e cromatografia líquida de alta eficiência (CLAE), os mais populares são os espectrofotométricos ultravioleta-visível (UV-VIS), fluorescência e eletroquímico. A detecção eletroquímica oferece vantagens sobre a detecção espectrofotométrica quando as espécies de interesse (analitos) não possuem um grupo cromóforo que absorve na região UV-VIS, ou quando as espécies apresentam baixo coeficiente de absorbância molar. Apresenta também vantagens sobre a detecção fluorimétrica de analitos eletroativos que não têm propriedades fluorescentes, porque não necessita da derivatização. ${ }^{1,2}$ Entre as técnicas eletroquímicas empregadas na detecção em fluxo, as mais exploradas são a coulometria e a amperometria devido a vantagens, tais como, baixo limite de detecção, seletividade e uso de instrumentação de baixo custo comparado aos empregados na detecção UV e fluorescência. ${ }^{3-8} \mathrm{Os}$ detectores amperométricos têm vantagens sobre os coulométricos, tais como, relação sinal/ruído mais satisfatória e configuração mais simples, sendo, por esta razão, mais utilizados. ${ }^{9}$

A detecção eletroquímica combinada à cromatografia líquida pode constituir-se numa ferramenta analítica potencialmente útil quando se deseja determinar compostos orgânicos em baixas concentrações, ou em nível de traços, em amostras de composição química altamente complexa como as de alimentos, ambientais e clínicas. ${ }^{10}$ Em princípio, somente os interferentes eletroativos que eluem da coluna cromatográfica, juntamente com as espécies do analito, e que sofrem processo eletroquímico (oxidação ou redução) na mesma região de potencial que as espécies do analito, devem ser separados do extrato da amostra. Assim sendo, a seletividade da detecção eletroquímica contribui para a simplificação da etapa de preparação da amostra para a análise cromatográfica. Além disso, a elevada sensibilidade da detecção eletroquímica para muitas espécies eletroativas diminui a necessidade de se empregar grandes quantidades (volume ou massa) de amostra e de solventes orgânicos, normalmente exigidos na etapa de preparação da amostra, para que o analito alcance níveis de concentração suficientes para ser detectado. ${ }^{11}$ Tais vantagens reduzem o tempo da análise e o consumo de solventes orgânicos, além de minimizar perdas do analito na etapa de preparação da amostra que afetam a reprodutibilidade do sinal analítico e os resultados da análise.

Os sistemas de análise por injeção em fluxo com detecção eletroquímica têm vantagens similares à cromatografia líquida com detecção

\footnotetext{
*e-mail: albuquerque@ufu.br
}

eletroquímica, exceto com relação à possibilidade da separação dos analitos pela coluna cromatográfica. Por esta razão, estes sistemas de análise são mais rápidos e exigem instrumentação simples para manter a solução eletrolítica carregadora sob fluxo e fazer as injeções de alíquotas da solução amostra no caminho da solução carregadora. Porém, nesses sistemas, o detector eletroquímico operando a potencial constante não discrimina os analitos eletroativos que têm processo eletroquímico no potencial aplicado. Essa limitação tem sido contornada na análise simultânea de alguns compostos eletroativos por meio da detecção amperométrica de múltiplos pulsos (AMP), também conhecida como amperometria pulsada. ${ }^{4,5}$ Embora a AMP esteja disponibilizada há algum tempo, esta técnica tem sido pouco explorada em determinações simultâneas de compostos eletroativos em sistemas de análise em fluxo. Chang e Huang utilizaram a AMP para determinar simultaneamente $\mathrm{Cd}^{2+}$

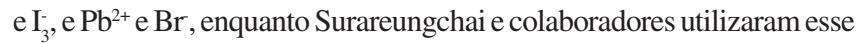
modo de detecção na determinação simultânea de glicose e frutose. ${ }^{12,13}$ Aplicações da técnica AMP em sistemas de análise por injeção em fluxo para a determinação simultânea de fármacos foram recentemente investigados pelo presente grupo de pesquisa. ${ }^{14,15}$

As células eletroquímicas em fluxo podem ser confeccionadas em configurações diversas, sendo as de camada delgada e wall-jet as mais comuns. Em ambas as configurações, as espécies do analito são transportadas por convecção até distâncias bem próximas do eletrodo de trabalho. A partir desta distância tem-se um filme de solução estagnado (conhecido como camada difusão de Nernst), na qual as espécies do analito alcançam a superfície do eletrodo somente por difusão, cuja taxa de transporte é controlada pelo gradiente de concentração resultante do consumo das espécies do analito na reação de eletrodo. Em princípio, o jato de solução que é produzido na entrada da célula wall-jet contribui para que as espécies do analito sejam transportadas até distâncias mais próximas da superfície do eletrodo de trabalho do que as do filme de solução nos detectores de camada delgada. ${ }^{16,17}$ Como resultado, um maior número de espécies do analito pode alcançar a superfície do eletrodo por unidade de tempo e produzir um sinal eletroquímico de maior intensidade. Os fundamentos do funcionamento da célula eletroquímica wall-jet foram desenvolvidos e publicados por Yamada e Matsuda. ${ }^{18}$ Diferentes geometrias de células funcionando segundo o princípio wall-jet estão descritas na literatura para uso em cromatografia líquida e sistemas de análise por injeção em fluxo. ${ }^{18-25}$

As principais dificuldades operacionais associadas aos detectores eletroquímicos em fluxo disponíveis no mercado, ou construídos em laboratório, devem-se ao fato da solução fluir sob pressão ao longo 
de células fechadas. Assim, os eletrodos e as tubulações devem estar firmemente ajustados ao corpo da célula para evitar qualquer tipo de vazamento, pois estes causam alterações na pressão do sistema, resultando em oscilações no sinal do detector e inviabilizando a análise. Por esta razão, esforços têm sido feitos para reduzir a frequência com que estas células devem ser desmontadas, seja para remover gases aprisionados no interior da célula, que tenham sido desprendidos ou formados nas reações de eletrodo, como também para realizar a limpeza mecânica da superfície do eletrodo de trabalho. A passivação do eletrodo de trabalho devido à adsorção de produtos da reação eletroquímica, ou de outras espécies presentes na solução sob estudo, é um problema muito frequente e deve ser evitado ou minimizado para se garantir a estabilidade da resposta do eletrodo. Cabe destacar ainda que a estabilidade da resposta do eletrodo pode ser estendida por um período de tempo maior utilizando-se métodos de detecção baseados na aplicação de pulsos de potenciais, que variam periodicamente, para a detecção do(s) analito(s) e limpeza eletroquímica da superfície do eletrodo. ${ }^{24,25} \mathrm{~A}$ amplitude, polaridade e tempos de aplicação dos pulsos de potencial, de detecção e limpeza podem ser variados no sentido de se garantir a maior sensibilidade e estabilidade do sinal eletroquímico. O ciclo de aplicação dos pulsos de potenciais de detecção é aplicado continuamente ao longo da análise. Embora os métodos de limpeza eletroquímica sejam muito úteis para se garantir a estabilidade da resposta dos detectores durante a análise, estes procedimentos não eliminam a limpeza mecânica do eletrodo, especialmente quando as espécies se encontram fortemente adsorvidas sobre o eletrodo. A desmontagem da célula para remover bolhas ou realizar a limpeza mecânica do eletrodo de trabalho é, em geral, uma tarefa difícil de se realizar, para muitos detectores em fluxo comerciais, ou mesmo para os construídos em laboratório, porque frequentemente provoca vazamentos, os quais são dificilmente solucionados.

O presente trabalho propõe uma célula eletroquímica wall-jet, construída em vidro, que opera sob condições de pressão atmosférica, para uso em CLAE e sistemas de análise por injeção em fluxo. A configuração da célula elimina dificuldades associadas à limpeza mecânica ou à substituição do eletrodo de trabalho, além de permitir o uso de qualquer eletrodo de trabalho, comercial ou confeccionado em laboratório como, por exemplo, os eletrodos metálicos, carbono vítreo e demais eletrodos de carbono, modificados e não modificados. Investigações da performance da célula como detector para CLAE e sistemas de análise por injeção em fluxo foram conduzidas.

\section{PARTE EXPERIMENTAL}

\section{Descrição da célula eletroquímica em fluxo}

A Figura 1 apresenta o esquema da célula eletroquímica em fluxo proposta.

A célula consiste de um tubo de vidro (1) com dimensões que podem ser ajustadas de acordo com as dimensões dos eletrodos utilizados. A extremidade inferior deste tubo (1) é vedada por uma peça de teflon (2) que tem um orifício longitudinal posicionado no centro da mesma. Dentro deste orifício é inserido um tubo de aço inoxidável (3) com um fino capilar (ao redor de 200-300 $\mu \mathrm{m}$ d.i.), para a entrada da solução eletrolítica, sendo o orifício da saída deste tubo (3) posicionado frontalmente ao centro do eletrodo de trabalho. Num sistema de análise por injeção em fluxo, o tubo (3) é conectado a uma tubulação de polímero inerte que transporta a solução do eletrólito carregador (ou a alíquota da solução amostra injetada). Num sistema de análise cromatográfica, o tubo de aço inoxidável (3) pode ser a própria tubulação que sai da coluna de separação cromatográfica. Na extremidade superior do tubo de vidro (1) encontra-se outra peça de teflon (4) dotada de um orifício longitudinal, com rosca interna. O diâmetro deste orifício é ajustado de acordo com o diâmetro externo de um tubo de teflon (5) que se ajusta ao redor do corpo do eletrodo de trabalho (6). O tubo de teflon (5) tem uma rosca externa que permite fazer o ajuste da distância do eletrodo de trabalho à saída do jato pelo orifício do tubo (3). O eletrodo auxiliar (7), que completa o circuito da eletrólise, e o eletrodo de referência (8), que controla o potencial aplicado ao eletrodo de trabalho, são posicionados próximos ao eletrodo de trabalho, em lados opostos. A solução na célula é transportada para um reservatório de descarte pela saída (9). O eletrodo auxiliar pode ser um fio de $\mathrm{Pt}$ (ou outro metal) e o eletrodo de referência pode ser um microeletrodo de $\mathrm{Ag} / \mathrm{AgCl}$ imerso numa solução de $\mathrm{KCl}$ (normalmente 3,0 mol L-1), que faz contato com a solução em fluxo por meio de uma junção porosa. ${ }^{26} \mathrm{O}$ eletrodo de trabalho é um eletrodo planar (por exemplo, um disco de 2,5 a $3 \mathrm{~mm}$ de diâmetro), e pode ser comercial ou confeccionado em laboratório.
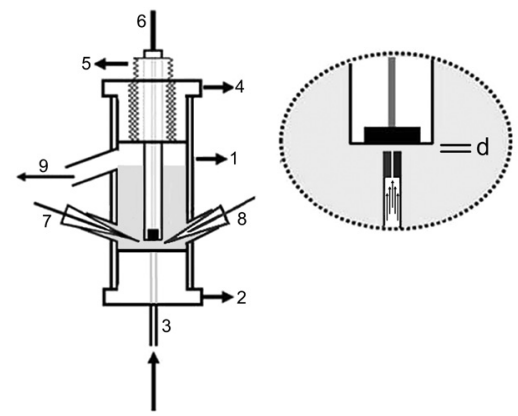

Figura 1. A) Célula eletroquímica “wall jet”. B) Vista de frente do eletrodo de trabalho e da saída do jato

No presente trabalho foram usados os eletrodos comerciais de ouro $(\mathrm{Au})$ e de carbono vítreo, da Metrohm, e um eletrodo de pasta de carbono confeccionado em laboratório. O eletrodo de pasta de carbono foi preparado a partir da mistura de $0,100 \mathrm{~g}$ de grafite puro (Fluka) em pó com $50 \mu \mathrm{L}$ de óleo mineral em um almofariz de ágata, até completa homogeneização. A pasta obtida foi inserida no interior de um tubo de polietileno, na extremidade inferior, tendo um fio de cobre como contato elétrico. Os eletrodos comerciais de Au e de carbono vítreo foram polidos numa suspensão aquosa de alumina e o eletrodo de pasta de carbono foi polido sobre papel vegetal até obter uma superfície lisa e de brilho metálico.

Antes de iniciar as medidas eletroquímicas, o eletrodo de trabalho era submetido a um tratamento eletroquímico na fase móvel usada na análise CLAE, ou na solução carregadora usada no sistema de análise por injeção em fluxo. Esse tratamento foi realizado por varredura cíclica de potencial, controlando-se principalmente os limites de potenciais anódicos para se evitar uma alta taxa de oxidação da superfície do eletrodo, que pode resultar na passivação ou na destruição do mesmo. A varredura de potencial foi repetida por 5 a 10 ciclos. Em seguida, o eletrodo de trabalho foi submetido a pulsos de potenciais de detecção e de limpeza eletroquímica, de magnitudes e de polaridade dependentes das espécies de interesse, até que a corrente residual monitorada pelo detector atingisse um valor estável na fase móvel ou na solução carregadora.

\section{Soluções e reagentes}

Todas as soluções foram preparadas com água deionizada (18 M $\Omega \mathrm{cm}$ ) obtida de um sistema de purificação Milli-Q.Plus (Millipore). As soluções utilizadas foram preparadas com reagentes de pureza analítica. Nas investigações em sistemas de análise por injeção em fluxo foram utilizadas soluções tampão ácido acético/acetato de sódio (Vetec) $0,05 \mathrm{~mol} \mathrm{~L}^{-1}$ (pH 5,0) e ácido cítrico (Vetec) $0,05 \mathrm{~mol} \mathrm{~L}^{-1}$ como solução transportadora. Soluções padrão estoque de nitrofenol, metil paration, fenitrotion, etil paration, ácido ascórbico, dipirona e paracetamol, todos 
de procedência Sigma-Aldrich ${ }^{\circledast}$, foram preparadas em concentração de $1000 \mathrm{mg} \mathrm{L}^{-1}$, em acetonitrila. As respectivas soluções de trabalho foram preparadas por diluição da solução estoque nos eletrólitos suporte ou fase móvel, antes do uso. Solução de $\mathrm{K}_{4} \mathrm{Fe}(\mathrm{CN})_{6}$ (Vetec) 1,0 x $10^{-3} \mathrm{~mol} \mathrm{~L}^{-1}$ foi preparada em tampão acetato $0,1 \mathrm{~mol} \mathrm{~L}^{-1} \mathrm{e}$ usada na caracterização do detector eletroquímico. Acetonitrila de grau cromatográfico e espectroscópico (Merck) foi usada nas investigações da célula como detector em cromatografia líquida de alta eficiência.

\section{Instrumentação}

As medidas amperométricas em fluxo foram realizadas utilizando-se o equipamento potenciostato/galvanostato PGSTAT 20 da Autolab (Eco Chemie). Um sistema de controle da vazão baseado na pressão gerada por uma coluna de água foi utilizado nas investigações da célula proposta em sistemas de análise por injeção em fluxo. ${ }^{27}$ As análises cromatográficas foram realizadas utilizando-se o equipamento da Shimadzu - Modelo LC-10AVP, dotado de um detector UV - Modelo SPD-10 AVP.

\section{RESULTADOS E DISCUSSÃO}

A célula eletroquímica proposta neste trabalho foi inicialmente caracterizada quanto à dependência do sinal eletroquímico com o "volume efetivo" da célula. Este volume é controlado pela área do eletrodo de trabalho e pela distância entre a superfície deste eletrodo e a saída do jato, indicado por "d" na Figura 1B. Como a área do eletrodo é constante, o "volume efetivo" da célula será controlado pela distância "d". Os sinais amperométricos obtidos em função da distância "d" para injeções de 100 $\mu \mathrm{L}$ de $\mathrm{K}_{4} \mathrm{Fe}(\mathrm{CN})_{6} 1,0 \times 10^{-3} \mathrm{~mol} \mathrm{~L}^{-1}$ num sistema de análise por injeção em fluxo, tendo tampão acetato $0,10 \mathrm{~mol} \mathrm{~L}^{-1}$ como solução carregadora, estão apresentados na Tabela 1. Pode-se observar pelos resultados da Tabela 1 que a distância "d" pode variar desde 1,0 até $4,0 \mathrm{~mm}$, sem causar alterações significativas na resposta do detector. O "volume morto" da célula é definido pelo volume restante ocupado pela solução eletrolítica e é significativamente maior do que o "volume efetivo". Como o "volume morto" não tem qualquer efeito na sensibilidade da resposta do detector, a célula pode ter as dimensões desejadas pelo usuário.

Tabela 1. Área do pico ( $\mu \mathrm{A}$ min) e altura do pico amperométrico $(\mu \mathrm{A})$ obtidos para $100 \mu \mathrm{L}$ de $\mathrm{K}_{4} \mathrm{Fe}(\mathrm{CN})_{6} 1 \times 10^{-3} \mathrm{~mol} \mathrm{~L}^{-1}$ em função da distância " $d$ ", entre a superfície do eletrodo de trabalho e a saída do jato.

\begin{tabular}{lcc}
\hline Distância “ $d$ ” $(\mathrm{mm})$ & Área do pico $(\mu \mathrm{A}$ min $)$ & Altura do pico $(\mu \mathrm{A})$ \\
\hline 1,0 & 9,83 & 1,65 \\
2,0 & 9,77 & 1,64 \\
4,0 & 9,10 & 1,55 \\
6,0 & 8,69 & 1,48 \\
8,0 & 8,27 & 1,40 \\
10,0 & 7,06 & 1,23 \\
\hline
\end{tabular}

A performance da célula eletroquímica como detector eletroquímico de um sistema CLAE foi investigada comparando-se a resolução da separação cromatográfica de uma mistura de nitrofenol (NF), metil paration (MP), fenitrotion (FE) e etil paration (EP) com a obtida com detector UV comercial. Para a separação cromatográfica da mistura de nitrofosforados utilizaram-se $20 \mu \mathrm{L}$ da solução sob estudo e uma coluna de separação de fase reversa C18 (CLC-ODS, nas dimensões $15 \mathrm{~cm}$ x 4,6 mm d.i.). Como fase móvel foi utilizada uma mistura de acetonitrila e ácido cítrico $0,05 \mathrm{~mol} \mathrm{~L}^{-1}$ na proporção 63:37. Os analitos eluídos da coluna cromatográfica foram monitorados sequencialmente pelo detector UV comercial e, então, pelo detector eletroquímico proposto, utilizando-se carbono vítreo como eletrodo de trabalho. Para garantir a estabilidade da resposta do detector durante um tempo prolongado utilizou-se a detecção amperométrica pulsada, que consiste em aplicar periodicamente pulsos de potencial $\mathrm{E}_{1}$ e $\mathrm{E}_{2}$, durante curtos períodos de tempo, da ordem de milisegundos (ms), para a detecção do analito e limpeza eletroquímica da superfície do eletrodo. A corrente faradaica produzida é monitorada somente no final da aplicação do pulso, quando a contribuição da corrente capacitiva é menor.

Esse modo de detecção oferece vantagens sobre a detecção amperométrica convencional porque a reação eletroquímica é permitida ocorrer somente durante um curto período de tempo, diminuindo problemas de passivação do eletrodo pelos produtos ou intermediários formados na reação. A passivação do eletrodo pode ser também minimizada pela aplicação sequencial do pulso de potencial $\mathrm{E}_{2}$, de valor suficientemente grande e de polaridade inversa à de $\mathrm{E}_{1}$, para promover reações eletroquímicas que eliminem qualquer espécie adsorvida na superfície do eletrodo. A aplicação de mais de um pulso de detecção e/ou de limpeza pode ser também utilizado para aumentar a seletividade e a estabilidade do sinal eletroquímico.

Os nitrocompostos separados pela coluna cromatográfica foram monitorados pela aplicação de pulsos sucessivos de $-0,6 \mathrm{~V}$ e, então, pulsos de limpeza eletroquímica do eletrodo de trabalho, na região anódica e na região catódica. O pulso de limpeza na região catódica tem valor inferior ao da detecção. Um ou mais pulsos podem ser usados para a limpeza eletroquímica do eletrodo de trabalho, desde que o tempo total envolvido nesta etapa não comprometa a amostragem do sinal de detecção. $\mathrm{Na}$ análise de nitrocompostos, uma boa estabilidade foi obtida com a aplicação de pulsos de limpeza de $+0,7$ e de $-0,2 \mathrm{~V}$. A duração de cada pulso foi de $100 \mathrm{~ms}$. Os pulsos de detecção e de limpeza eletroquímica foram aplicados sequencialmente e sucessivamente durante toda a análise cromatrográfica. No potencial de $-0,6 \mathrm{~V}$ as espécies do analito são detectadas pela corrente produzida na redução eletroquímica do grupo nitro $\left(-\mathrm{NO}_{2}\right)$ à hidroxilamina $(-\mathrm{NHOH}) .{ }^{28}$ Os sinais cromatográficos obtidos pelo detector comercial UV e detector eletroquímico proposto estão apresentados na Figura 2. As resoluções da separação cromatográfica de
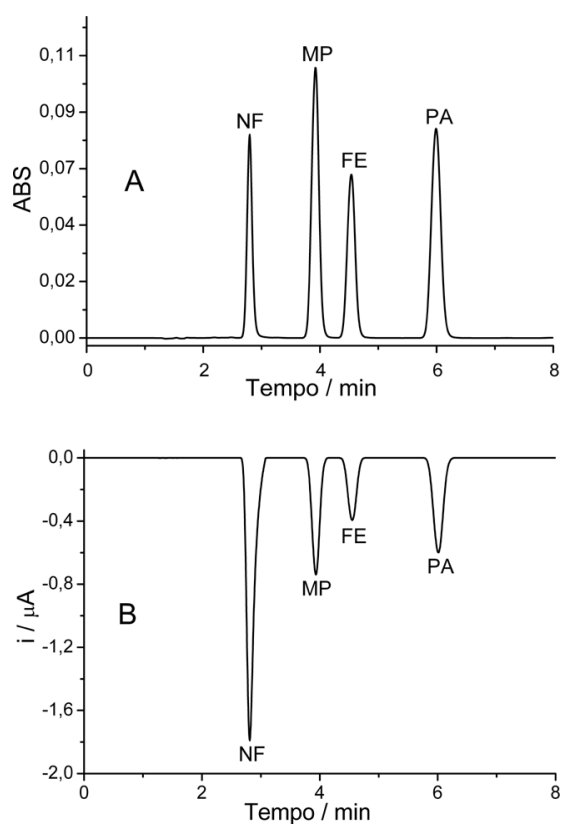

Figura 2. Cromatogramas obtidos com (A) detector UV comercial (273 nm) $e(\boldsymbol{B})$ detector eletroquímico proposto (-0,60 V vs $\mathrm{Ag} / \mathrm{AgCl})$, para Nitrofenol (NF), Metil Paration (MP), Fenitrotion (FE) e Paration (PA), em 1,0 $\mathrm{mg} \mathrm{L}^{-1}$ cada. Coluna de separação: CLC-ODS, $15 \mathrm{~cm} \times$ 4,6 mm d.i. Fase móvel: acetonitrila e ácido cítrico 0,05 $\mathrm{mol} \mathrm{L}^{-1}$, 63:37, sob vazão de 1,0 $\mathrm{mL} \mathrm{min}^{-1}$. Volume da solução: $20 \mu \mathrm{L}$ 
NF-MP, MP-FE, e FE-PA foram calculadas, respectivamente, em 3,0; 1,4 e 2,9 utilizando-se o detector UV comercial, e em 2,7; 1,5 e 3,3 usando a detecção amperométrica com a célula proposta. A resolução dos picos cromatográficos indica que o detector eletroquímico tem performance comparável à do detector UV, não se observando qualquer efeito de alargamento da banda ou aparecimento de cauda. Estes resultados indicam que o detector não apresenta efeitos de residência ou de memória, e que os analitos são monitorados pelo detector tão rapidamente quanto são eluídos da coluna cromatográfica.

Outra característica importante apresentada pela célula proposta é a facilidade com que o eletrodo de trabalho pode ser retirado da célula, seja para realizar a limpeza mecânica (ou polimento) ou para ser substituído por outro eletrodo com características eletroquímicas mais adequadas para a detecção de interesse. Para tanto, basta que o eletrodo tenha dimensões adequadas para se manter firmemente preso no interior do tubo de teflon (5) da Figura 1 e se mantenha posicionado a pelo menos 4,0 mm de distância da saída do jato de solução. Em adição, o desprendimento de gases dentro da célula não causa variações na pressão do sistema e nem afeta o contato elétrico entre os eletrodos e a solução. O detector eletroquímico pode ser usado ainda com diferentes eletrodos de trabalho, comerciais e confeccionados em laboratório, sejam estes modificados ou não modificados. Cabe destacar que o uso de eletrodo modificado pode aumentar a seletividade do detector eletroquímico e favorecer os processos de transferência de carga na interface eletrodo-solução. Pode ainda inibir a formação de filmes que passivam a superfície do eletrodo ou possibilitar a concentração das espécies de interesse sobre o eletrodo, contribuindo para uma resposta mais rápida, de maior sensibilidade e estabilidade. ${ }^{29,30}$ A possibilidade de se usar qualquer tipo de eletrodo de trabalho, ou de substituir tal eletrodo quando as limpezas eletroquímica e mecânica não são suficientes para recuperar a área eletroquimicamente ativa, diminui as limitações da detecção eletroquímica e amplia as aplicações desse modo de detecção para uma diversidade de analitos eletroativos, orgânicos e inorgânicos. A Figura 3 apresenta os sinais cromatográficos obtidos pelo detector eletroquímico proposto para uma mistura de ácido ascórbico, dipirona e paracetamol $\left(4,0 \times 10^{-5} \mathrm{~mol} \mathrm{~L}^{-1}\right.$ cada), utilizando três eletrodos de trabalho diferentes: pasta de carbono (PC) confeccionado em laboratório, e eletrodos comerciais de carbono vítreo $(\mathrm{CV})$ e de ouro $(\mathrm{Au})$. As condições da separação cromatográfica foram as mesmas utilizadas na análise da mistura de nitrocompostos, exceto pela proporção de acetonitrila e ácido cítrico na fase móvel. Os sinais cromatográficos foram obtidos pela aplicação de pulsos sucessivos de $+0,80$ e $-0,10 \mathrm{~V}$ vs $\mathrm{Ag} / \mathrm{AgCl}$, durante $100 \mathrm{~ms}$, sendo o primeiro para a detecção dos fármacos separados pela coluna cromatográfica e o segundo para a limpeza eletroquímica do eletrodo. Observa-se pelos sinais cromatográficos da Figura 3 que o tipo de eletrodo de trabalho afeta somente a magnitude do sinal eletroquímico, mantendo praticamente inalterada a resolução da separação cromatográfica dos fármacos.

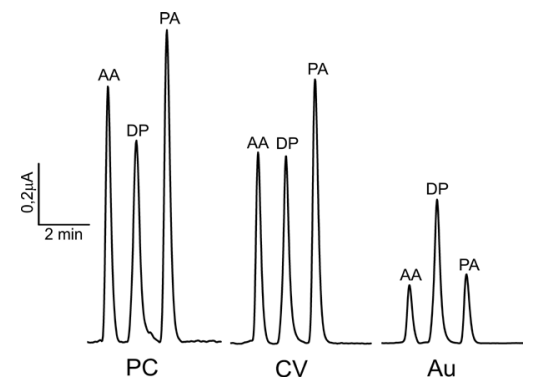

Figura 3. Cromatogramas obtidos de uma mistura de Ácido Ascórbico (AA), Dipirona (DP) e Paracetamol (PA), em concentração de 4,0 $\times 10^{-5} \mathrm{~mol} \mathrm{~L}^{-1}$ cada. Eletrodo de trabalho: pasta de carbono $(P C)$, carbono vítreo $(C V) e$ ouro (Au). Coluna de separação: CLC-ODS, $15 \mathrm{~cm} \times 4,6 \mathrm{~mm}$ d.i.. Fase móvel: acetonitrila e ácido cítrico 0,05 $\mathrm{mol} \mathrm{L}^{-1}, 20: 80$, sob vazão de 1,0 $\mathrm{mL} \mathrm{min}^{-1}$. Volume da solução: $20 \mu \mathrm{L}$
A Figura 4 mostra a estabilidade da resposta do detector, tendo carbono vítreo como eletrodo de trabalho, para cinco injeções sucessivas de solução contendo ácido ascórbico, dipirona e paracetamol (em 2,5 x $10^{-5} \mathrm{~mol} \mathrm{~L}^{-1}$ cada). Os sinais eletroquímicos indicam que o tratamento eletroquímico do eletrodo e a aplicação de pulsos $+0,80$ e $-0,10 \mathrm{~V}$ vs $\mathrm{Ag} / \mathrm{AgCl}$, durante $100 \mathrm{~ms}$, para a detecção e limpeza eletroquímica do eletrodo, proporcionou uma resposta estável para os fármacos separados. Um desvio padrão relativo de $0,4 \%$ foi obtido para o ácido ascórbico, $0,6 \%$ para a dipirona e $0,3 \%$ para o paracetamol.

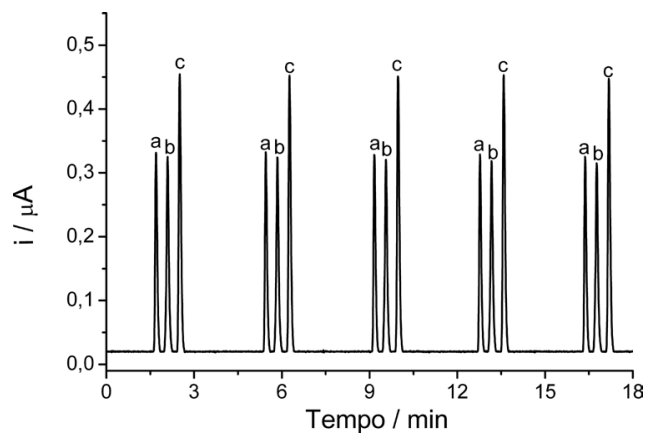

Figura 4. Cromatogramas obtidos da injeção sucessiva de solução contendo (a) ácido ascórbico, (b) dipirona e (c) paracetamol, em concentração $2,5 \times 10^{-5}$ mol $L^{-1}$ cada. Eletrodo de trabalho: carbono vítreo. Coluna de separação: CLC-ODS, $15 \mathrm{~cm} \times$ 4,6 mm d.i. Fase móvel: acetonitrila e ácido cítrico 0,05 mol $\mathrm{L}^{-1}$, 20:80, sob vazão de 1,0 $\mathrm{mL} \mathrm{min}^{-1}$. Volume da solução: $20 \mu \mathrm{L}$

Estudos da performance analítica do detector eletroquímico para organofosforados e derivados fenólicos em sistemas de análise por injeção em fluxo forneceram resultados similares, com sinais amperométricos bastante estáveis e uma relação sinal/ruído bastante satisfatória, possibilitando obter limites de detecção da ordem de 1,0 x $10^{-8} \mathrm{~mol} \mathrm{~L}^{-1}$ ou menores. Tendo-se em vista a resposta rápida e estável do detector eletroquímico, investigou-se o uso do mesmo no modo gerador-coletor. Nesse modo de detecção monitora-se o analito A num pulso de potencial $\mathrm{E}_{1}$, como também o respectivo composto $\mathbf{B}$ formado se este for eletroativo, num segundo potencial de detecção, $\mathrm{E}_{2}$. Se B produzir no potencial $\mathrm{E}_{2}$ um composto $\mathbf{C}$ também eletroativo, este poderá ser também monitorado pela aplicação de um terceiro pulso de potencial, $\mathrm{E}_{3}$. Devido a esse fato, a detecção no modo gerador-coletor aumenta a seletividade da análise porque permite diferenciar analitos que sofrem processo eletroquímico na mesma região de potencial, mas que produzem compostos com diferentes características eletroquímicas. Investigações do uso da célula como detector eletroquímico no modo gerador-coletor foram conduzidos utilizando-se metil paration. Este composto apresenta os processos eletroquímicos identificados como I, II e III, na Figura 5A, os quais correspondem, respectivamente, à redução do grupo nitro $\left(-\mathrm{NO}_{2}\right)$ a hidroxilamina $(-\mathrm{NHOH})$, oxidação do grupo hidroxilamina (-NHOH) a nitroso (-NO), e redução do grupo (-NO) a hidroxilamina (-NHOH) ${ }^{28}$ A Figura $5 \mathrm{~A}$ mostra que metil paration e os respectivos compostos $(-\mathrm{NHOH})$ e (-NO) podem ser detectados pelo detector eletroquímico se pulsos de potenciais de - $0,5,+0,4$ e $-0,1 \mathrm{~V}$ vs $\mathrm{Ag} / \mathrm{AgCl}$ forem aplicados sequencialmente, durante períodos de tempo suficientemente curtos para possibilitar a detecção dos produtos formados antes que estes difundam para regiões distantes do eletrodo. A Figura 5B mostra os picos amperométricos obtidos para injeções em triplicata de $300 \mu \mathrm{L}$ de solução de metil paration, na faixa de 50 a $250 \mu \mathrm{g} \mathrm{L}^{-1}$ nos respectivos potenciais de detecção, utilizando-se ácido cítrico 0,05 mol $\mathrm{L}^{-1}$ como solução carregadora. Os sinais amperométricos mostrados na Figura 5 indicam que a resposta do detector é suficientemente rápida para acompanhar os produtos formados na reação de eletrodo, quando o jato de solução colide com a superfície do eletrodo de trabalho. 
Observa-se que os sinais amperométricos monitorados nos três pulsos de potenciais aplicados apresentam repetibilidade bastante satisfatória para os níveis de concentração estudados. Uma relação linear entre os sinais amperométricos $(\mathrm{I})$ e a concentração de metil paration $\left(\mathrm{C}_{\mathrm{MP}}\right)$ foi obtida nos três potenciais de detecção, com um coeficiente de correlação linear ao redor de 0,997. As Equações obtidas foram: $\mathrm{I}(\mathrm{nA})=-3,57+$ $1,26 \mathrm{C}_{\mathrm{MP}}\left(\mu \mathrm{g} \mathrm{L}^{-1}\right)$ em $-0,5 \mathrm{~V} ; \mathrm{I}(\mathrm{nA})=-3,52+0,560 \mathrm{C}_{\mathrm{MP}}\left(\mu \mathrm{g} \mathrm{L}{ }^{-1}\right) \mathrm{em}+0,4$ $\mathrm{V}$ e I $(\mathrm{nA})=0,634+0,330 \mathrm{C}_{\mathrm{MP}}\left(\mu \mathrm{g} \mathrm{L}^{-1}\right)$ em $-0,1 \mathrm{~V}$.
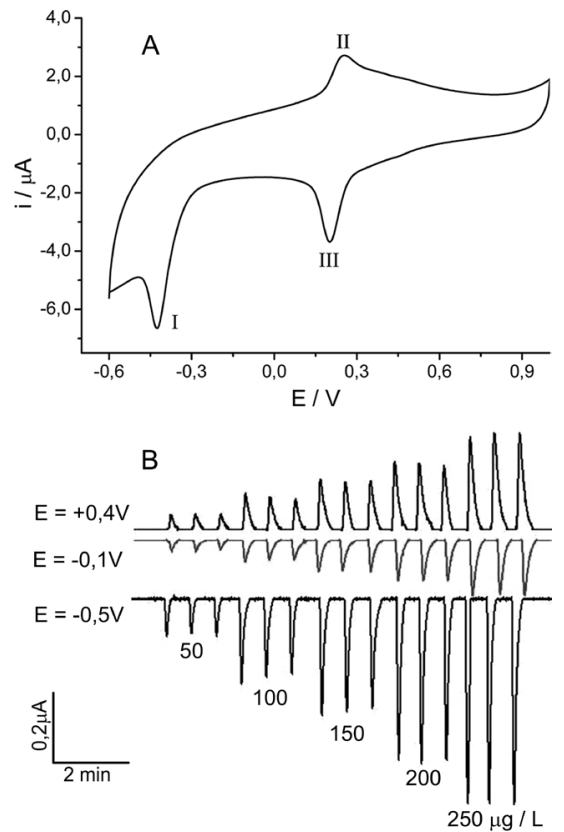

Figura 5: A) Voltamograma cíclico de metil paration $20 \mathrm{mg} \mathrm{L}^{-1}$ sobre carbono vítreo, em ácido cítrico $0,05 \mathrm{~mol} \mathrm{~L}^{-1}$. B) Sinais amperométricos obtidos da injeção em triplicata $(300 \mu \mathrm{L})$ de solução de metil paration, nas concen-

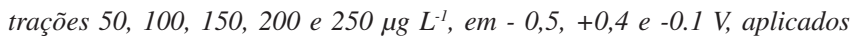
sequencialmente. Tempo de aplicação de cada pulso: $30 \mathrm{~ms}$. Eletrodo de trabalho: carbono vítreo. Solução carregadora: ácido cítrico 0,05 $\mathrm{mol} \mathrm{L}^{-1}$, sob vazão de 1,4 $\mathrm{mL} \mathrm{min}^{-1}$

\section{CONCLUSÕES}

A célula eletroquímica proposta neste trabalho pode ser utilizada como detector para CLAE e em sistemas de análise em fluxo. A célula funciona na configuração wall-jet e apresenta vantagens, tais como, resposta rápida, alta estabilidade e elevada sensibilidade na resposta do detector. A célula não apresenta efeitos de alargamento de banda e nem efeitos de memória, possibilitando o monitoramento dos analitos separados pela coluna cromatográfica com resolução comparável à do detector UV comercial. Além disso, a solução na célula flui sob pressão atmosférica, eliminando problemas de variações na pressão e de vazamentos. A geometria da célula permite que a limpeza mecânica do eletrodo de trabalho seja facilmente executada, além de possibilitar o uso de eletrodos de trabalho comerciais e confeccionados em laboratório. Estas vantagens aumentam a seletividade e a sensibilidade da detecção eletroquímica, possibilitando ampliar as aplicações desse modo de detecção para uma diversidade de analitos eletroativos, orgânicos e inorgânicos, especialmente os presentes em amostras de alimentos, medicamentos, fluidos biológicos, e amostras ambientais.

\section{AGRADECIMENTOS}

À CAPES e FAPEMIG pelas bolsas de mestrado concedidas e à FAPEMIG pela infraestrutura do laboratório de Instrumentação Analítica e Eletroquímica Aplicada, do Instituto de Química da Universidade Federal de Uberlândia (IQ-UFU), a qual viabilizou a execução desse trabalho.

\section{REFERÊNCIAS}

1. Baldwin, R. P.; J. Pharm. Biomed. Anal. 1999, 19, 69.

2. Kotani, A.; Kusu, F.; Takamura, K.; Anal. Chim. Acta 2002, 465, 199.

3. Johnson, D.; Weber, S. G.; Bond, A. M.; Wightman, R. M.; Shoup, R. E.; Krull, I. S.; Anal. Chim. Acta 1986, 180, 187.

4. Trojanowicz, M.; Szewczynska, M.; Wcislo, M.; Electroanalysis 2003, 15, 347.

5. Chailapakul, O.; Ngamukot, P.; Yoosamran, A.; Siangproh, W.; Wangfuengkanagul, N.; Sensors 2006, 6, 1383.

6. Yashin, Y. I.; Yashin, A. Y.; J. Anal. Chem. 2004, 59, 1121.

7. Galli, A.; De Souza, D.; Garbellini, G. S.; Coutinho, C. F. B.; Mazo, L. H.; Avaca, L. A.; Machado, S. A. S.; Quim. Nova 2006, 29, 105.

8. Lebiedzinska, A.; Marszall, M. L.; Kuta, J.; Szefer, P.; J. Chromatogr., A 2007, 71, 1173.

9. Kissinger, P.; Anal. Chem. 1977, 49, 447.

10. Klejdus, B.; Vacek, J.; Adam, V.; Zehnálek, J.; Kizek, R.; Trnková, L.; Kubán, V.; J. Chromatogr., B 2004, 101, 806.

11. Skrinjar, M.; Kolar, M. H.; Jelsek, N.; Hras, A. R.; Bezjak, M.; Knez, Z.; J. Food Comp. Anal. 2007, 20, 539.

12. Chang, C. M.; Huang, H. J.; Anal. Chem. 2003, 75, 6368.

13. Surareungchai, W.; Deepunya, W.; Tasakorn, P.; Anal. Chim. Acta 2001, 448, 215

14. Dos Santos, W. T. P.; de Almeida, E. G. N.; Ferreira, H. E. A.; Gimenes, D. T.; Richter, E. M.; Electroanalysis 2008, 20, 1878.

15. Dos Santos, W. T. P.; de Almeida, E. G. N.; Albuquerque, Y. D. T.; Eiras, S. P.; Gimenes, D. T.; Richter, E. M.; J. Braz. Chem. Soc. 2009, 20, 1249.

16. Dalhuijsen, A. J.; Van Der Meer, Th. H.; Hoogendoorn, C. J.; Hoogvliet, J. C.; Van Bennekom, W. P.; J. Electroanal. Chem. 1985, 182, 295.

17. Kubiak, W. W.; Strozik, M. M.; J. Electroanal. Chem. 1996, 417, 95.

18. Yamada, J.; Matsuda, H.; J. Electroanal. Chem. Interfacial Electrochem. 1973, 44, 189.

19. Fleet, B.; Little, C. J.; J. Chromatogr. Sci. 1974, 12, 747.

20. Verschraagen, M.; Zwiers, T. H. U.; Torun, E.; Donker, M. G.; Reinhoud, N. J.; Van Der Vijgh, W. J. F.; J. Pharm. Sci. 2003, 92, 1040.

21. Cannan, S.; Unwin, P. R.; Electroanalysis 2004, 16, 712.

22. Chang, J. L.; Zen, J. M.; Electrochem. Commun. 2007, 9, 2744.

23. Liao, C. Y.; Chang, C. C.; Ay, C.; Zen, J. M.; Electroanalysis 2007, 19, 65.

24. Fleet B.; Patent U.S. 4,059,406, 1977.

25. Berger T. A.; Patent E.P. 0140286 A2, 1984.

26. Pedrotti, J. J.; Angnes, L.; Gutz, I. G. R.; Electroanalysis 1996, 8, 673.

27. Dos Santos, W. T. P.; Ceolin, M. P.; de Albuquerque, Y. D. T.; Richter, E. M.; Quim. Nova 2007, 30, 1754.

28. Zen, J. M.; Kumar, S. A.; Anal. Chim. Acta 1999, 396, 39.

29. Agüí, L.; Pena-Farfal, C.; Sedeno, P. Y.; Pingarrón, J. M.; Anal. Chim. Acta 2007, 323, 585.

30. De la Fuente, C.; Acuna, J. A.; Vazquez, M. D.; Tascón, M. L.; Batanero, P. S.; Talanta 1999, 49, 441. 